\title{
ANGNGALLE ALLO: TRADISI DAN PERILAKU SOSIAL BUDAYA MASYARAKAT TURATEA
}

\section{Angngalle Alio: Tradition and Social and Culture Behavior of Turatea Community}

\author{
Muh. Jumatang Rate \\ Sekolah Tinggi Agama Islam Al-Amanah Jeneponto Karisa \\ J1. Pannara Kota Bontosunggu \\ Kabupaten Jeneponto Telp.(0419)2425858 \\ Email: jumatang.rate@yahoo.com
}

\begin{abstract}
Abstrak
Penelitian ini bertujuan menganalisa sistem kepercayaan angngalle alio dengan perilaku sosial budaya masyarakat Turatea Kabupaten Jeneponto. Penelitian ini termasuk penelitian kualitatif normatif. Dilihat dari perilaku masyarakat Turatea, penjelasan dan laporan terhadap fenomena yang akan dibahas, maka penelitian ini menggunakan pendekatan fenomenologi. Dalam pengumpulan datanya, penulis bertindak sebagai instrument penelitian, untuk mengumpulkan data sebagai bahan pengolahan. Data yang dikumpulkan meliputi sistem kepercayaan angngalle alio dan perilaku sosial budaya masyarakat Turatea. Data diperoleh melalui informan, dokumentasi dan pengamatan langsung kepada sosial budaya masyarakat tersebut. Teknik pengumpulan datanya dilakukan melalui melihat fenomena perilaku masyarakat Turatea, wawancara, dan, dokumentasi. Data yang diperoleh selanjutnya dianalisa dengan menggunakan analisa kategorisasi. Hasil penelitian ini menunjukkan bahwa angngelle alio sangat erat hubungannya sistem kepercayaan dengan perilaku sosial budaya yang sudah menjadi tradisi masyarakat Turatea sejak awal masuknya agama Islam di daerah ini, sekitar abad ke tujuh belas.
\end{abstract}

Kata kunci: angngalle alio, kepercayaan, perilaku sosial, budaya, masyarakat Turatea

\begin{abstract}
This study aims to analyze Angngalle Alio belief system and social and cultural behavior of Turatea community in Jeneponto. Study was qualitative normative. Based on observation on Turatea community behavior, and related reports, phenomenology approach was used in this study. To collect data on angngalle alio belief systems and socio-cultural behavior of Turatea, the authors act as a research instrument. Data obtained through informants, documentation and direct observation and analyzed categorically. Study shows that 'angngelle alio' belief system is closely related to community social and cultural tradition change since the coming of Islamic teachings around seventeenth century.
\end{abstract}

Keywords: angngalle alio, trust, social behavior, Turatea cultural society

\section{PENDAHULUAN}

pabila melihat fenomena alam dan
membaca secara saksama eksistensi
merilaku masyarakat sekitar, maka tak dapat dipungkiri bahwa tidak ada satu pun pemeluk agama di atas bumi ini mengingkari keniscayaan kematian (Hamka Haq, 2009: 83). Keniscayaan kematian di balik kehidupan akan terjadi pada setiap makhluk yang bernyawa, apakah ia dekat atau jauh. Kematian pasti terjadi bagi setiap makhluk yang hidup, tidak ada seorang pun manusia mengingkarinya apabila ajal seseorang datang menjemputnya. Sebagaimana dalam Alquran, Allah Swt berflrman dalam QS.Thaha/20: 15 "Sesungguhnya hart Kiamat itu akan datang Aku merahasiakan (waktunya) agar supaya tiap-tiap dirt itu dibalas dengan apa yang ia usahakan (Departemen Agama, 2004: 313). Selanjutnya Allah berfirman pula dalam QS. Thaha ayat 74-76 berikut terjemahnya "Sesungguhnya barangsiapa datang kepada Tuhannya dalam keadaan berdosa, maka sesungguhnya baginya neraka Jahannam. Ia tidak mati di dalamnya dan tidak (pula) hidup. Dan barangsiapa datang kepada 
Tuhannya dalam keadaan beriman, lagi sungguhsungguh telah beramal saleh, maka mereka itulah orang-orang yang memperoleh tempat-tempat yang tinggi (mulia), (yaitu) surga 'Adn yang mengalir sungai-sungai di bawahnya, mereka kekal di dalamnya. Dan itu adalah balasan bagi orang yang bersih (dari kekafiran dan kemaksiatan)

Angngalle alio merupakan salah satu sarana atau acara ritual keagamaan bagi masyarakat Turatea berkenaan meninggalnya salah seorang anggota keluarga, untuk menanamkan pesan-pesan yang bersifat edukatif-religius dan kepercayaan tentang keniscayaan akan datangnya hari akhirat yang dimulai dari kematian dan segala hal-ihwal yang berkenaan dengan kematian, akan datangnya hari pembalasan surga dan segala nikmatnya bagi pelaku kesalihan dan neraka dan segala azabnya bagi pelaku kejahatan.

Masyarakat Turatea merupakan sapaan akrab bagi penduduk asli yang mendiami kabupaten Jeneponto Propinsi Sulawesi Selatan. Kabupaten Jeneponto merupakan salah satu daerah tingkat II yang terletak di ujung bagian barat dati wilayah Propinsi Sulawesi Selatan yang secara geografis berada atau terletak di antara koordinat $5^{\circ} 10^{\prime} 13$ - 5³9'35 lintang Selatan dan antara 12'40'1912'75'51" Bujur Timur, dengan luas wilayah Kabupaten Jeneponto memiliki luas 79.979 Ha, atau 749,79 $\mathrm{Km}^{2}$.

Menilik latar belakang di atas, maka dengan judul penelitian ini Angngalle Alio: Tradisi dan Perilaku Sosial Budaya Masyarakat Turatea, penulis merumuskan beberapa sub masalah. Dalam penelitian ini, angngalle alio adalah merupakan kepercayaan masyarakat Turatea, yang sudah membudaya dalam hati masyarakat, yang sering dilaksanakan berkenaan meninggalnya seseorang anggota keluarga masyarakat Turatea, dengan acara-acara keagamaan yang sudah berakar dalam hati masyarakat Turatea, sehingga menjadi keharusan sebagai penawar duka, pelipur lara karena kematian, menghilangkan kesedihan dan kesusahan hati karena kehilangan anggota keluarga. Sehingga dengan terlaksananya acara angngalle alio tersebut hilanglah kesedihan mereka, karena sudah terhibur dengan pesan-pesan atau nasehatnasehat agama, melalui dengan doa dan pengajian Kitab Suci Alquran pada malam-malam pra acara puncak dengan diselang-selingi bacaan Kittak Badul Akhirat, sampai hari $\mathrm{H}$ acara angngalle alio, sebagai acara puncak. permasalahan dalam penelitian ini adalah: bagaimana peran tradisi angngalle alio dalam kehidupan sosial budaya masyarakat Turatea?, dan bagaimana peran nasehat dalam kittak badul akhirat dalam tradisi pangajian angngalle alio?.

\section{Tinjauan Pustaka}

Berbagai penelitian tentang masyarakat dan tradisi keagamaannya telah banyak dilakukan khususnya oleh para insan akademik maupun para peneliti, akan tetapi berkaitan dengan tema angngalle alio: tradisi dan perilaku sosial budaya masyarakat, masih sedikit atau bahkan belum ada yang melakukan riset berkaitan dengan hal tersebut. Oleh karena itu, dalam kajian pustaka ini, peneliti hanya akan mendeskripsikan beberapa rujukan teori-teori ilmiah yang dianggap relevan di antaranya sebagai berikut: Masyarakat Muslim Makassar: Studi Polapola Integrasi Sosial antara Muslim Pagama dengan Muslim Sossorang, Nurman Said, Disertasi 2009, UIN Sunan Kali Jaga. Penelitian ini menjelaskan pola-pola integrasi sosial antarkomunitas muslim Makassar, sangat berbeda dengan tema peneliti, tetapi disertasi ini bisa dijadikan referensi dalam menjaga integrasi sosial antarkomunitas muslim di Jeneponto (Nurman Said, 2009).

Agama Dalam Kehidupan Manusia, Bustanuddin Agus, Rajawali Press, 2007. Dalam buku tersebut banyak dimuat pelbagai teori ilmiah tentang agama, aspek-aspek kehidupan agama, agama dan sistem sosial budaya dari perspektif antropologi agama (Bustanuddin Agus, 2007). Bagi peneliti, kajian yang dibahasa dalam buku tersebut ini sangat membantu dalam penelitian ini.

Agama dan Budaya dalam Integrasi Sosial (Belajar dari Masyarakat Fak-Fak di Propinsi Papua Barat, Saidin Ernas dkk, Harmoni Volume 13, Nomor 1, Januari-April 2014, Jurnal Puslitbang Kehidupan Keagamaan Kementerian Agama (Saidin Ernas dkk, 2014: 22-35). Dalam penelitian menjelaskan bahwa agama dan budaya berperan penting dalam melahirkan norma-norma sosial yang harmonis yang mempengaruhi praktik-praktik sosial individu hingga pada arena sosial yang lebih luas seperti politik dan ekonomi. Hasil penelitian dapat juga dijadikan sebagai acuan/referensi dalam mengembangkan hasil penelitian di masyarakat Turatea, Jeneponto.

Kebudayaan, Perubahan Sosial dan Agama dalam Perspektif Antropologi, Kurnia Novianti, Harmoni Volume 12, Nomor 2, Mei-Agustus 2013, Jurnal Puslitbang Kehidupan Keagamaan Kementerian Agama. Penelitian ini menjelaskan tentang dialektika isu-isu kebudayaan, perubahan 
sosial, dan agama untuk menjelaskan fenomenafenomena yang diamati dalam kehidupan seharihari, yang bertujuan untuk memberikan sebuah perspektif dalam memahami arti fenomena yang diamati dan dianalisis melalui pengungkapan "catatan tersembunyi" di belakang fenomena itu (Kurnia Novianti, 2013: 8-20).

\section{Metode Penelitian}

Penelitian ini adalah penelitian lapangan (Field Research). Jenis penelitian adalah kualitatifdeskriptif, yang bertujuan untuk mencari penjelasan tentang angannge alio di masyarakat Turatea. Adapun pendekatan yang digunakan dalam penelitian ini multidisipliner yang meliputi pendekatan sosiologis dan fenomenologi. Guna memahami pendekatan tersebut, maka penulis memaparkan pengertiannya sebagai berikut: Pendekatan Sosiologis. Sosiologi adalah ilmu yang mempelajari interaksi yang terjadi dalam masyarakat. Sosiologi merupakan ilmu yang membahas mengenai berbagai gejala yang timbul dalam masyarakat. Dengan demikian, sosiologi sangat erat kaitannya dengan pembahaSan tentang perubahan sosial. Perubahan sosial adalah suatu perubahan dari kondisi tertentu dalam masyarakat. Konsep perubahan sosial akan sangat penting digunakan untuk melihat berbagai perubahan yang terjadi dalam masyarakat khususnya mengenai aksi interaksi sosial yang ada di dalam masyarakat (Ary H. Gunawan, t.t.: 3-5).

Pendekatan ini diharapkan mampu mengungkap perubahan sosial yang terjadi dalam masyarakat Turate Kab. Jeneponto. Pendekatan fenomenologi. Istilah fenomenologi berasal dari bahasa Yunani pahainomenon yang secara harfiah berarti "gejala" atau "apa yang telah menampakkan diri" sehingga nyata bagi kita (Ambo Upe, 2010: 33-35). Fenomenologi berusaha memahami budaya lewat pandangan pemilik budaya atau pelakunya. Menurut paham fenomenologi, ilmu bukanlah value free, bebas nilai dari apapun, melainkan values bound, memiliki hubungan dengan nilai (Suwardi Endraswara, 2006: 65).

Pendekatan ini diharapkan mampu menggali pandangan-pandangan masyarakat Turatea mengenai angngalle alio. Melalui beberapa pendekatan tersebut di atas, diharapkan mampu mengungkap berbagi macam hal sesuai dengan obyek penelitian. Metode pengumpulan data menggunakan teknik observasi dengan cara pengumpulan data yang dapat dilakukan secara pengamatan langsung, sistematis, dan sengaja melalui pengamatan dan pencatatan terhadap obyek yang diteliti (Laksono, 1999: 6). Wawancara dilakukan kepada informan ahli/narasumber dalam hal ini adalah tokoh masyarakat Turatea. Narasumber tersebut dianggap berkompeten dijadikan informan. Wawancara yang dilakukan pada umumnya adalah wawancara tidak terstruktur namun mencakup seluruh pokok masalah penelitian. Adapun wawancara terstruktur hanya bersifat konfirmasi ulang kepada tokoh masyarakat/tokoh agama dalam beberapa hal yang dianggap belum jelas. Dokumentasi. Dokumentasi, yaitu mendapatkan data sekunder dengan cara mempelajari dan mencatat arsip-arsip atau dokumen laporan kegiatan dan lain-lain yang berhubungan dengan penelitian ini. Jenis data adalah kualitatif yang bertujuan untuk mencari penjelasan tentang angngalle alio, nilai-nilainya, dan implikasinya terhadap kehidupan mereka, serta kemungkinan adanya kearifan lokal yang baik untuk menuju masa depan yang lebih baik lagi.

Metode pengolahan data menggunakan metode kualitatif- deskriptif. Metode kualitatifdeskriptif adalah menggambarkan dan memaparkan data-data hasil penelitian, baik yang bersumber dari wawancara, observasi, dan dokumentasi, dengan berupa kalimat-kalimat atau paragraf-paragraf bukan berupa angka-angka statistik atau bentuk angka lainnya (Miles dan Huberman, 1984: 10).

\section{PEMBAHASAN}

Angngalle alio merupakan salah satu kebudayaan masyarakat Turatea yang tertua bersifat religius berkenaan adanya keluarga yang meninggal dunia. Angngalle alio merupakan bagian dari kekayaan kebudayaan Indonesia sebagaimana pengertian kebudayaan yang mencakup hasil kegiatan dan penciptaan batin (akal budi) manusia seperti kepercayaan, kesenian, adat istiadat (Departemen Pendidikan dan Kebudayaan, 2000:149). Selain itu, Alo Liliweri mengutip Edward T. Hall menjelaskan bahwa kebudayaan adalah komunikasi, dan komunikasi adalah kebudayaan. Dalam artian bahwa hanya manusia berbudaya yang berkomunikasi, dan ketika manusia berkomunikasi dia dipengaruhi oleh kebudayaannya (Alo Liliweri, 2005: 361).

Begitu pula pengertian kebudayaan yang diutarakan oleh Hartomo dan Arnicun Aziz bahwa wujud kebudayaan adalah kelakuan berpola dari manusia dalam masyarakat, misalnya manusia melakukan kegiatan berinteraksi sosial, 
berhubungan dan bergaul satu sama lain (Hartomo, 1999: 13). Dengan demikian, Angngalle alio dapat dimasukkan bagian dari kebudayaan karena di dalam acara tersebut individu dapat berinteraksi sosial antara satu individu dengan individu lainnya. Oleh karena itu, Angngalle alio sebagai budaya sosial masyarakat Turatea telah mendarah-daging dan sangat sukar diubah serta dihapuskan walaupun perkembangan dan kemajuan pemahaman masyarakat terhadap hakikat ajaran agama Islam yang mereka anut semakin meningkat.

Dewasa ini, sesuai dengan perkembangan dan kemajuan zaman modern ini, tradisi masyarakat Turatea angngalle alio' disebut juga 'al-ta'ziah' fpernyataan belasungkawa dan berdukacita) (Ahmad Warson, 1984: 997). Tradisi angngalle alio biasanya dilaksanakan pada hari puncak peringatan hari kematian, yaitu; tallung ngallona (hari yang ketiga dari kematian seorang anggota keluarga dari masyarakat turatea), limang ngallona (hari yang kelima), tujuh ngallona (hari yang ke tujuh), salapang ngallona (hari yang kesembilan) atau hari-hari ganjil sesudah hari yang ketiga dari kematian seseorang atau acara tersebut dilakukan sesuai dengan kemampuan keluarga almarhum/ almarhumah. Adakalanya tradisi angngalle alio' dilaksanakan pada sampulo ngallona (hari yang ke sepuluh), ruampulo allona (hari yang kedua puluh) patampulo allonna (hari yang ke empat puluh), sibilangngan allonna (hari yang keseratus) dan tammu taunna (hari setahunnya dari kematian seseorang anggota masyarakat turatea) (Jumateng Rate, 1983: 20-21). Setelah melaksanakan puncak acaranya angngalle alio, maka hari-hari berikutnya tidak lagi pelaksanaan hari peringatan kematian bagi si mayit.

Tradisi angngalle alio bagi masyarakat Turatea di laksanakan apabila terjadi kematian dari anggota masyarakat tersebut. Selain itu, acara tersebut juga merupakan wadah silaturahim dengan karib kerabat, handai taulan, baik dari keluarga dekat dan maupun keluarga yang berada di luar daerah. Sebagaimana diutarakan oleh Emile Durkheim bahwa agama berperan sebagai perekat sosial, hal ini ditandai dengan tradisi angngalle alio yang sertamerta masyarakat Turatea berbondong-bondong untuk menghadiri acara tersebut (Moh. Soehadha, 2008: 12). Tradisi angngalle alio mempunyai arti penting, sehingga bagi kerabat si mayit, di mana dan kapan pun akan meluangkan waktu untuk menghadiri puncak acara tersebut yang dikenal sebagai "punna niallei allonna" (acara puncak dari tazkirah).
Masyarakat Turatea mengenal kepercayaan bahwa si mayit atau orang yang baru berpisah dengan rohnya, belum sepenuhnya pergi meninggalkan dunia fana ini, tetapi masih berada di sekeliling kediamannya dan menyaksikan cucu, anak dan karib kerabatnya yang berduka cita atas kepergiannya ke alam akhirat. Selain itu, dalam masyarakat Turatea pula kepercayaan bahwa roh si mayit membutuhkan rasa kasih sayang dari keluarga yang ditinggalkannya, sehingga bagi keluarga khususnya bagi kaum perempuan menjadi keharusan untuk menyiapkan makanan, lauk pauk dan minuman secukupnya, walaupun hanya ala kadarnya sepiring nasi dan sebutir telur ketika waktu makan telah tiba yang diperuntukkan bagi si mayit. Hal ini dilakukan tiap malam sebelum tiba hari puncak memperingati hari kematian dalam tradisi masyarakat Turatea. Menyiapkan dan menghidangkan makanan bagi si mayit dalam tradisi ini dikenal dengan istilah "kanre allo-allonna" (makanan sehari-hari) sebelum bepergian jauh meninggalkan sanak saudaranya. Berkenaan dengan hal ini, terkadang ada ungkapan yang tak tertulis dan sangat dipercaya mengatakan bahwa "alusu'na dawana tau matea, kasara'na dawana tau tallasaka" (batinnya hidangan itu bagi si mayit, dan zhahirnya bagi orang-orang yang hidup).

Tradisi angngalle alio telah tumbuh dalam masyarakat Turatea, hal ini ditegaskan oleh salah satu tokoh masyarakat Turate, H. Baso Dg Lala, ia mengatakan:

Punna tena nipam-macangngi biasai battu nyawana taumatea angtu mange ri bijanna nabokowiya, akpala kakdok, lampa nakana angngapa natena kamma nusarea kangrenu? Sekre alio mateipurinangku ri Bantaeng, mingka angjo purinnangku tau Muhammadiah, jari tena nipamma-cangngi, sekre waktu ammempomempoma ri ballakku (ri Bongtoramba), tikring tassoyokmi matangku, nakucinik battu purinangku, nakkana mae rinakke, "angngapai anak natena kamma nusarea kangrenu natallungngalloma tena kuangngare, sannakmi cipurukku anne". Lekbaki angjo tassakringma, naku kana ri bainengku ammolongko jangan nanipammacangngi purinayya kuciniki baktu akpalak kangre sannaki cipurukna nakana. Apaji nakummolongmo jangan lampa kupakpalak dowangngan. Angtu kittak badul akhirat sampan niak tau mate nibacangji sanggenna kamma-kamma angne, yakkannengpayya biasai tena nisakringngi singara nibaca sanggenna 
barikbasak punna lekbami tauwa angngaji (wawancara tanggal 31 Agustus 2014 di Masjid Besar Bonto Ramba).

(Roh si mayit biasa datang kepada keluarganya yang ditinggalkan meminta sesuatu berupa makanan dengan berkata mengapa tidak memberikan makan kepadaku? Pernah suatu hari didatangi oleh paman yang telah wafat, ia semasa hidupnya aktif di organisasi Muhammadiyah di Bantaeng, sebagaiman diketahui bahwa orang Muhammadiyah jikalau meninggal tidak akan dibacakan atasnya sesuatu, dalam tidur, tiba-tiba paman saya mendatangiku dan berkata mengapa kamu tidak memberikan kepadaku makan? padahal saya sudah lama tidak makan tidak ada sesuatu pun yang masuk di perutku sehingga saya sangat lapar, kemudian saya terbangun dari tidur kemudian mendatangi istriku dan berkata saya melihat paman datang meminta makanan katanya lapar sekali. Maka saya pun menyembelih seekor ayam dan mendoakan kepada pamanku.

Betapa kokohnya kepercayaan acara 'angngalle alio' ini di tengah masyarakat Turatea sehingga kalau teradat karib kerabat atau handai taulan yang meninggal tanpa diperingati hari kematiannya, tidak dilaksanakan (nialle allonna) sering ada ungkapan, 'Mate jangan sikayui iyanu tena niallei allonna (berpulangnya sifulan laksana matinya seekor ayam tanpa dipeingati kematiannya). Dan hal tersebut sering menjadi buah bibir di kalangan masyarakat, apa lagi kalau keluarga si mayit orang yang berada atau keluarga bangsawan.

\section{Pangngajian}

Pembacaan Alquran setiap malam sampai acara puncak (angngalle alio) sebagai doa bagi si mayit, dalam masyarakat Turatea dikenal dengan istilah "pangngajian". Selain itu, setelah pembacaan Alquran selesai, maka akan dilanjutkan pembacaan 'Kittak Badul Akhirat'. Kittak Badul Akhirat merupakan salah satu karya seni dalam bahasa daerah Makassar dengan menggunakan Aksara Arab (aksara serang). Kitab ini juga biasa disebut Kittak Tulkiamah, atau yang dikenal dengan nama Kitabu Akhbaar al-Akhirah. Selanjutnya dalam penelitian nama kitab tersebut akan digunakan secara bergantian.
Pembacaan Kittak Badul Akhirat dalam masyarakat Turatea mempunyai arti penting, hal ini ditegaskan oleh Sampara Dg Pasi (Kepala Imam Kampung Taba, umur 75 tahun), ia berkata:

Antu Kittak Badul Akhirat biasai nibaca punna
niak tau mate, nipaklekbasang angngajia
Kurangan, punna lekbamo tauwa angngaji
nibacami antu Kittaka sanggenna lantang
bangngiya, yakkannengpaya sanggenna singarak
sannak nangaina napilangngeri baik-baikneya.
Anne Tau matea appakaramula nipangngajian
siagang nipaklebasang ammaca Kittak Badul
Akhirat, sipattanna sanggenna narapi nialle
allonna" (Wawacara tanggal 25 Agustus 2014
di Kampung Taba). (Kitab badul akhirat itu
sering dibaca, bila ada orang yang meninggal,
diselang-selingi dengan pengajian Alquran, bila
orang sudah membaca Alquran dibacalah kitab
ini sampai jauh malam, bahkan sampai siang,.
Pembacaan "Kittak Badul Akhirat" di mulai
sejak malam pertama dari meninggalnya hingga
tiba puncak acara hari kematiannya (nialle
allonna)".

Sampara Dg Pasi menandaskan bahwa pembacaan kittak Badul Akhirat mendapatkan posisi yang penting di tengah masyarakat Turatea, sehingga tidak afdal membaca Alquran bagi si mayit tanpa membaca kitab ini. Sebab kitab ini dapat dijadikan pelipur lara dikala duka dan penghibur di kala sedih. Begitu pula, bagi yang mendengar pembacaan Kittak Badul Akhirat dapat meningkatkan keimanan kepada Allah Swt, sebab banyak berisi nasehat-nasehat perlunya mawas diri dalam menghadapi kematian.

Senada dengan di atas, Muhammad Nasir (Tokoh Agama Kec. Bangkala) mengatakan bahwa:

Antu kittak badul akhirat tenamemangtodok
tau tangalannasak atinna punna napilangngerei
nibaca" (Hasil wawancara tanggal 26 Agustus
2014 di Bangkala). (Kittak Badul Akhirat
itu, tidak ada orang yang tak sedih bila ia
mendengarkan, dan memperhatikan (Kittak
Badul Akhirat) itu dibaca).

Lain halnya dengan $\mathrm{H}$. Muhammad Zainal (Pengurus Masjid Agung Jeneponto) yang melihat dari sisi materi ketika diadakan pembacaan Kittak Badul Akhirat setelah pembacaan Alquran, ia mengatakan: 
Rua'i kittak lintak sikali nigappa pammajikinna iyami angtu Barasanjia siagang 'kittak badul akhiraf, nasaba sampan lekbaki ammaca barasanji iyareka ammaca kittak badul akhirat, langsungki angnganre kangre jawa siagang anggakpa tongki pole amplok (Hasil wawancara tanggal 26 Agustus 2014 di masjid Masjid Agung Jeneponto). (Ada dua kitab cepat sekali kita memperoleh kebaikan darinya yaitu kitab barasanji dan kittak badul akhirat, setiap selesai membacanya langsung kita makan kue dan mendapatkan amplop).

Pelbagai pernyataan di atas, pangngajian bagi masyarakat Jeneponto memberi arti tersendiri di dalam kehidupannya, ada yang memaknainya sebagai doa yang diberikan terhadap si mayit, ada juga yang memaknainya sebagai keuntungan materi bagi yang ikut pangngajian tersebut.

Kittak Badul Akhiratmenjadi salah satu bagian yang terpenting dari pangngajian ini, olehnya itu penelahaan pesan-pesan religius dalam Kittak Badul Akhirat juga sangat urgen. Peneliti hanya akan mendeskripsikan sekelumit pesan-pesan religius dalam kittak ini yang terdiri atas tujuh bab.

1. Bab uru-urunayya ampaknassai kajarianna Nurun Muhammad, (Bab pertama menceritakan tentang kejadian Nur Muhammad).

2. Bab maka ruwana ampaknassai kajarianna nabi Adam, (Bab yang kedua menceritakan kejadian Nabi Adam).

3. Bab maka talluna ampaknassai kajariyanna mateya siagang pammallokinna mateya (Bab yang ke tiga menceritakan tentang kematian dan segala hal ihwalnya).

4. Bab maka akpakna ampaknassai kana-kananna Kiyamaka (Bab yang ke empat menceritakan hari Kiamat)..

5. Bab maka limana ampaknassai gaukna Kiamaka siagang pammallokinna Kiamaka (Bab yang ke lima menceritakan hari Kiamat dan huruharanya).

6. Bab maka annanna ampaknassai kana-kananna Naraka siagaang bonena (Bab yang ke enam menceritakan neraka dan isinya serta segala azabnya).

7. Siagang bab maka tujuna ampaknassai kanakananna suruga siagang bonena (Bab yang ketujuh menceritakan surga dan segala isinya serta nikmatnya).

Yang sering dibaca pada malam-malam pra angngalle alio, biasanya tidak dimulai dari bab pertama tentang kejadian Nur Muhammad, tetapi biasanya dimulai pada bab ketiga tentang kematian dan seterusnya, yakni tentang hari kiamat, neraka dan surga.

Dalam tulisan ini hanya kami tampilkan sekelumit mulai dari bab yang ketiga sebagai kaitannya dengan acara angngalle alio sebagaimana dimaksud pokok bahasan:

Bab yang ke tiga menceritakan kematian dan keadaan dan hal ihwal mati itu sendiri, ketahuilah wahai sekalian orang yang beriman kepada Allah Ta'ala dan kepada kematian, dalam hadis diceritakan sesungguhnya Allah Ta'ala menciptakan mati itu seorang malaikat yang sangat besar, kemudian dihijab/diselimuti oleh Allah Ta'ala mati itu dengan sepuluh ribu lapis pembungkus. Adapun besarnya malaikat itu lebih besar dari pada tujuh tingkat langit dan tujuh lapis bumi. Kemudian dirantai dengan tujuh ribu rantai, setiap rantai ditempuh tujuh ratus tahun lamanya, seandainya ditempuh oleh malaikat untuk mendekatinya, maka tidak ada seorang pun malaikat yang bisa mendekatinya, kecuali terdengar hanya suara, tetapi tidak diketahui yang punya suara itu.

Setelah Adam as diciptakan, barulah Allah Ta'ala memberikannya, agar dipegang oleh malaikat Izrail mati itu, tetapi malaikat Izrail minta ampun seraya berkata apakah mati itu wahai Tuhan? Maka Allah pun minta kepada Izrail agar membuka penutup mati itu, maka terlihatlah bagi Izrail wajah mati itu. Berfirmanlah Allah Ta'ala kepada semua malaikat berdirilah kalian semua agar melihat mati itu. Maka berdirilah semua malaikat melihat mati itu. Berfirmanlah Allah Ta'ala; Wahai mati bentangkanlah sayapmu dan bukalah matamu! Maka mati pun membentangkan sayapnya dan membuka matanya, maka pingsanlah dia (melihat wajah Tuhannya) selama seribu tahun, setelah sadar dari pingsannya mintalah ampun dan berkata wahai Tuhan, masihkah ada makhluk yang Engkau ciptakan lebih besar dari mati ini?,

Berfirmanlah Allah Ta'ala hanya Akulah yang menciptakan mati itu dan Akulah yang lebih besar dari padanya. Dan semua makhluk itu akan merasakan kematian. Berfirmanlah Allah, wahai Izrail, Aku menyerahkan kepadamu mati ini, Aku menganggap kamulah yang lebih kuat dari mati itu. Minta ampunlah Izrail dan berkata: Wahai Tuhanku, aku tidak mampu memegang mati itu, karena dia lebih besar dari aku. Maka Allah Ta'ala pun memberikan kekuatan kepada Izrail, dan mampulah ia memegang mati itu, maka mintalah ampun mati itu kepada Allah seraya berkata; 
Wahai Tuhan ku izinkanlah aku memanggil satu kali kepada semua isi langit dan bumi, Allah Ta'ala pun mengizinkan memanggil. Dan memanggillah mati itu dengan sekeras-keras suara, ia berkata: Saya inilah yang disebut mati, sayalah yang memisahkan setiap orang yang saling mencintai, memisahkan anak dari ibunya, memisahkan suami dengan isterinya, memisahkan persaudaraan, dan sayalah yang mengalahkan setiap orang yang kuat dari anak cucu Adam, sayalah ini yang menghancurkan sebuah kota dan menjadikan sunyi semua kampung halamannya. Dan sayapulalah mendapati orangyang bersembunyi sekalipun berada di peti besi, karena tidak ada seorang pun akan lepas dari kematian, kecuali semuanya itu pasti akan merasakan mati).

Napunna nakaerokimo tassitau atanna Allah Ta'ala mate, mammentengmi mateya angtu ri dallekanna kuntu todongrupanna tau lamateya angtu naciniki kamma ilalang carangmeng, nakanamo tau alamateya angtu, inaiko angtu, nakanamo mateya inakkey minney niareng mate ampassuluki tauwa ri lino, nabalumo pakkalabineyanna, namakukangmo anak-anakna, nanitawamo bararcg-barangna. Napunna nalangngerekmo pakkananna mateya antu napasek-lengmi matanna rupanna mange ri kanang mange ri kairi, kuntuiji nacini ri dallekangna nakanamo malakulmauti tenaka nuasengnga inakke minney malakulmauti angngallei nyawana manggenu, naikau niyajako mannangarak mangey, anne attuwa tenamo nakguna ri kau, anne wattuwa lakualletommi nyawanu sollanna nanacinikko anaknu, siagang bela-belanu. Anne allowa tenamo matu-matunna barang-barangnga siagang anaka, passangalinna tau nipa-salamaka ri Karaeng Allah Ta'ala.

Bila Allah Ta'ala mau mewafatkan seseorang dari hamba-Nya yang meninggal, berdirilah mati itu di depan orang yang akan mati, seperti wajahnya orang yang akan meninggal, ia melihat seperti dalam cermin/kaca rasa. Berkatalah orang yang dalam sekarat, siapakah engkau, berkatalah mati; sayalah yang disebut mati, mengeluarkan manusia dari dunia, sehingga jandalah seorang isteri, menjadi duda seorang suami, dan yatimlah anak-anaknya, dan semua hartanya dibagi-bagikan. Setelah orang dalam sekarat mendengar ucapan malakul maut, berpalinglah ia ke kanan dan ke kiri, di saat itu berkatalah mati tidakkah kamu tahu bahwa sayalah malakul mauti yang telah mengambil nyawa bapakmu, sedang kamu ada melihatnya, pada waktu ini tidak ada lagi alasan bagimu, nisacaya aku juga mengambil nyawamu, agar anakmu juga dapat melihat dan memandang kepadamu dan sahabat hanadai tolanmu. Pada hari ini tidak bergunalagi harta dan anak, kecuali orang yang diselamatkan oleh Allah Ta'ala).

Antu empowanna mateya rateyannai langit makatujuwa, sekre riwayat ri langit maka appaka, nipakjari ri Karaeng Allah Ta'ala baktu risingaraka tujuh pulo sakbuna bangkenna, patasskbu kaknyikna, rassi batangkalenna mata siagang Mia, siagang manna sekre risikungtu maknyawayya tamaniyak kurang ri kalenna mateyya rupanna, matanna, siagang tolinna singjai bilanna tauwa. Napunna naallemo nyawana tauwa limannami angtu napaalle, nannangaramo ri rupanna assuluk tommi angtu nyawayya, siagang mate tommi angtu tau mateyya. Kuntumi angjo gaukna mangngallena nyawa ri sikungtu mukhalloka, ri tungga-tunggalak tampak, napunna matei tassitau tauwa ri lino aklampami battu ri batangkalenna sangrapang rupanna angtu.

Kedudukan malakul maut itu berada di atas langit yang ke tujuh, dalam satu riwayat dikatakan pada langit yang ke empat. Allah Ta'ala menciptakannya dari cahaya, baginya tujuh puluh ribu kaki, dan empat ribu sayapnya, di sekujur tubuhnya ada wajah, mata, lidah, telinga sebanyak bilangan manusia. Apabila ia mengambil nyawa seseorang dia mengambil dengan tangannya, maka memandanglah orang itu kepada wajahnya dan keluarlah nyawa/roh itu, maka matilah manusia itu. Demikianlah cara malaikat mengambil nyawa seseorang pada setiap tempat, dan apabila seseorang meninggal dunia, keluarlah dari jasadnya gambar wajahnya seperti dirinya sendiri.

Sekre riwayat angkana antu mateya akpaki rupanna. Sekre ri dallekanna; sekre ri ulunna, sekre ri bokona, sekre ri bangkenna. Napunna naallei nyawana tassitau-tauwa nabokoki siagang malaikakah rupa ri ulunna angngallei, napunna naalle nyawana tau matakpaka rupa ri dallekanna angngallei, napunna naalle tassiatau tau kapereka rupa ri bokona angngallei siagang punna nyawana jinnga siagang syetangnga, olok-oloka rupa ri bangkenna angngallei. Nabangkengna mateya angtu siwali mangngongjok ri biringna suruga, siwali mangngongjok ri biringna naraka. Nalompona kalenna angtu mateya kakammaji nialle jeknek tamparangnga siagang jeknek binangayya nanitirik rate ri ulunna tabattuwai manawung ri bauttyya manna siattik.

Dalam sebuah riwayat dikatakan; bahwa mati itu mempunya empat wajah (muka) satu di depan, satu di belakang, satu di kepalanya, dan satu lagi di 
kakinya. Dan apabila ia mengambil nyawa seseorang dari nabi, rasul dan malaikat dia mengambil dari wajah di kepalanya, jika ia mengambil nyawanya seseorang mukmin di ambil dari wajah depannya, dan bila ia mengambil nyawanya seseorang kafir dia mengambilnya dari wajah belakangnya, dan apa bila ia mengambil nyawanya seseorang jin, setan, atau binatang ia mengambil dari wajah kakinya. Dan kaki mati itu satu mengingjak di pinggir surga, dan satu lagi menginjak di pinggir neraka. Dan besar badannya si mati itu, seandainya semua air laut dan air sungai dituangkan di atas kepalanya, tidak ada yang sampai ke bumi se tetespun.

Sekre riwayat angkanai, sitojeng-tojengna
Allah Ta'ala ampakjari linowa ri dallekanna malakulmauti, sangrapanji dulangnga ri dallekangna tau akkadoka, nanakakdok keremae nakaeroki, kungtumi angtu malakulmauti naalena nyawana sikungtu makhalloka iyya-iyyannamo nakaerokiya. Angtu malakulmauti napassing-kammaji linowa benggoloka nabulik-bulintak keremae nakaeroki, kamma tommi angjo batena naalle nyawana sikungtu makhalloka iyyak-iyyannamo nakaerokiyya.

Dalam sebuah riwayat dikatakan; Sesungguhnya Allah Ta'ala menjadikan dunia itu di depan malakulmauti, seakan-akan sama dengan dulan di depan seseorang yang mau makan, kemudian dia makan di atas dulan itu yang mana saja dia ingini. Demikian jugalah malakulmauti mengambil nyawanya makhluk yang mana saja dia inginkan. Dan bagi malakulmauti duniya ini laksana mata uang dinar, dia mudah memainkannya membalik-balik kemana dia suka, demikian jugalah dia mengambil nyawa makhluk yang dia inginkan.

Bertanyalah Malakulmaut kepada Allah Ta'ala, Ya Tuhan bagaimana caranya aku mengambil nyawa hamba-Mu? Berfirmanlah Allah Ta'ala wahai Malakulmaut! Hal tersebut adalah pengetahuan$\mathrm{Ku}$, tidak ada yang mengetahui siapapun dari makhluk kecuali Aku sendiri. Dan apabila telah sampai ajal seseorang dari hamba-Ku, ada malaikat $\mathrm{Aku}$ perintahkan mengurusi rezkinya, ada yang mengurus ajalnya, ada yang mengurus nafasnya, dan ada juga yang mengurus amalnya, mereka itulah yang memberitahukan kamu, mereka berdiri di depanmu masing-masing berkata; Akulah yang mengurus umurnya dan sekarang sudah habis, ada yang mengatakan akulah yang mengurus rezkinya, tetapi sekarang sudah habis, ada yang mengatakan akulah yang mengurus amalnya dan sekarang sudah habis amalnya si pulan. Kalau orang yang akan mati adalah dari golongan orang-orang celaka, maka malakulmaut itu menulis namanya dengan tinta hitam, kemudian diperlihatkan kepada Allah Ta'ala. Tetapi kalau orang yang akan mati itu adalah orang yang berada dari golongan orang-orang yang berbahagia, maka malakulmauti menulis namanya dengan tinta putih bercahaya yang sangat terang mengelilinginya di saat itu matilah hamba Allah. Dikatakan ada satu pohon di bawah Arasy tertulis nama setiap orang di atas daunnya setiap lembar tiap orang. Dan apabila daun itu gugur jatuh ke depan Malakulmaut, lalu diambilnya dan melihat nama siapa yang tertulis di atas lembaran daun tersebut, dan nama itulah yang diambil oleh Malakulmaut. Ka'ab al-Ahbar berkata: Sesungguhnya Allah Ta'ala telah menjadikan satu pohon kayu di bawa Arasy, namanya Syajaratulmuntaha dari tiap-tiap daunnya tertulis setiap nama sebanyak bilangan makhluk, semuanya tertulis di atas daun tersebut. Dan apabila seseorang dari hamba Allah Ta'ala akan meninggal empat puluh hari sebelumnya jatulah daun yang tertulis nama seseorang itu ke depan Malakulmaut, dan melihat tulisan namanya si fulan, dan yang punya nama itulah yang diambil nyawanya, penghuni langit berkata telah meninggal si fulan tetapi masih ada di bumi. Diperintahkanlah malaikat jannanna (wakilnya Malakulmaut) pergi mengambil nyawa seseorang tersebut, malaikat penghuni langit itu berkata telah mati si fulan tapi masih ada di bumi. Dan apabila daun pohon yang jatuh itu, adalah daun tuanya, maka yang akan meninggal itu adalah orang tua juga akan mati. Dan kalau daun mudanya jatuh, maka anak mudalah atau gadis akan mati, tetapi kalau daun pucuknya yang jatuh, maka yang akan mati adalah bayi.

Nakana Faqihu abu Laitsa rahmatullah alaih, napunna mambanimo mate tassitau tau atanna Allah Ta'ala niyak tukguruk irawangnganna Arasy, ruwallawara sala sekrenna antu taukiri rilekok mongcong bulowa iyareka ri lekok keboka, napunna lekok kebok tukguru tau matowa antu lamate, punna lekok mongcong bulo tukguru tau cilaka angtu lamate. (Seorang ahli fiqh Abu Laist semoga Allah memberikan rahmat, ia berkata; Apabila seseorang dari hamba Allah Ta'ala sudah mendekati ajal kematiannya, ada dua lembar daun yang jatuh di bawa Arasy, daun putih dan daun hijau. Kalau daun putih itu jatuh, maka yang meninggal itu adalah orang yang berbahagia (ahli surga), dan apabila daun hijau itu jatuh, maka.yang akan meninggal itu adalah orang celaka).

Bertanyalah Malakulmaut kepada Allah Ta'ala, Ya Tuhan bagaimana caranya aku mengambil 
nyawa hamba-Mu? Berfirmanlah Allah Ta'ala wahai Malakulmaut! Hal tersebut adalah pengetahuan-Ku, tidak ada yang mengetahui siapapun dari makhluk kecuali Aku sendiri. Dan apabila telah sampai ajal seseorang dari hamba-Ku, ada malaikat Aku perintahkan mengurusi rezkinya, ada yang mengurus ajalnya, ada yang mengurus nafasnya, dan ada juga yang mengurus amalnya, mereka itulah yang memberitahukan kamu, mereka berdiri di depanmu masing-masing berkata; Akulah yang mengurus umurnya dan sekarang sudah habis, ada yang mengatakan akulah yang mengurus rezkinya, tetapi sekarang sudah habis, ada yang mengatakan akulah yang mengurus amalnya dan sekarang sudah habis amalnya si fulan. Kalau orang yang akan mati adalah dari golongan orang-orang celaka, maka malakulmaut itu menulis namanya dengan tinta hitam, kemudian diperlihatkan kepada Allah Ta'ala. Tetapi kalau orang yang akan mati itu adalah orang yang berada dari golongan orang-orang yang berbahagia, maka malakulmauti menulis namanya dengan tinta putih bercahaya yang sangat terang mengelilinginya di saat itu matilah hamba Allah.

Dikatakan ada satu pohon di bawah Arasy tertulis nama setiap orang di atas daunnya setiap lembar tiap orang. Dan apabila daun itu gugur jatuh ke depan Malakulmaut, lalu diambilnya dan melihat nama siapa yang tertulis di atas lembaran daun tersebut, dan yang punya nama itulah yang diambil oleh Malakulmaut. Ka'ab al-Ahbar berkata: Sesungguhnya Allah Ta'ala telah menjadikan satu pohon kayu di bawah Arasy, namanya Syajaratulmuntaha dari tiap-tiap daunnya tertulis setiap nama sebanyak bilangan makhluk, semuanya tertulis di atas daun tersebut. Dan apabila seseorang dari hamba Allah Ta'ala akan meninggal empat puluh hari sebelumnya jatulah daun yang tertulis nama seseorang itu ke depan Malakulmaut, dan melihat tulisan namanya si fulan, dan yang punya nama itulah yang diambil nyawanya, penghuni langit berkata telah meninggal si fulan tetapi masih ada di bumi.

Diperintahkanlah malaikat jannanna (wakilnya Malakul-maut) mengambil nyawa mahluk, malaikat penghuni langit itu berkata telah mati si fulan tapi masih ada di bumi. Dan apabila daun pohon yang jatuh itu, adalah daun tuanya, maka yang akan meninggal itu adalag orang tua juga akan mati. Dan kalau daun mudanya jatuh, maka anak mudalah atau gadis akan mati, tetapi kalau daun pucuknya yang jatuh, maka yang akan mati adalah bayi.
Mengenal tempat kematian seseorang hamba Allah Ta'ala, Allah swt menyuruh seorang malaikat menulis nama dan tempat kematiannya, sebab kematiannya, kemudian dia bawa ke Malakalmauti, dan Malakulmautilah yang mengambil nyawanya si hamba itu karena Allah. Dikatakan; ada juga malaikat dijadikan oleh Allah Ta'ala yang mewakili setiap orang yang dilahirkan disebut malakul arham namanya. Apabila Dia menjadikan anak itu dalam rahim ibunya, malaikat Al-arham itu diperintahkan mengambil tanah dari mana dia akan mati dan dikuburkan kemudian dicampur dengan air mani yang ada di dalam rahim ibunya. Dan setelah anak tersebut ditakdirkan lahir ke bumi sekalipun dia mengelilingi dunia tidak akan mati sebelum sampai kepada tanah dari mana ia dicampurkan kejadiannya sebagai tempat kematiannya dan kuburannya, dan di atasnyalah tanah itu dia meninggal. Sejalan dengan firman Allah Surah Ali Imran ayat 154 yang terjemahnya: ..... Katakanlah: (Muhammad)"Sekiranya kamu berada di rumahmu, niscaya orang-orang yang telah ditakdirkan akan mati terbunuh itu ke luar (juga) ke tempat mereka terbunuh". Dari ayat ini terkandung maksud bahwa sekalipun tinggal diam di dalam rumah, di tempat tidur, akan tetapi ketentuan Allah swt sudah mencatat di tempat manakah kematian akan menjemput?.

Diceritakan dalam sebuah riwayat, bahwa pada suatu hari Malakalmaut menampakkan dirinya kepada seorang anak muda yang berada di dekat Nabi Sulaiman, anak muda tersebut melihat seorang lelaki perkasa di dekat nabi Sulaiman, bila memandang kepada anak muda menggetarlah badannya anak muda itu, seakan-akan hancur tulang belulangnya melihat tamu Nabi Sulaiman. Setelah pergi tamu Nabi Sulaiman, maka mintalah anak muda itu kepada Nabi Sulaiman agar memerintahkan angin untuk menerbangkan dirinya ke kampung yang namanya Sanggaleyya.

Maka diterbangkanlah anak muda itu oleh angin sampai di Kampung yang namanya Sanggaleyya. Setelah itu, datang lagi Malakulmauti kepada Nabi Sulaiman, berkatalah kepadanya Nabi Sulaiman kenapa kamu menatap wajah anak muda tadi, Malakulmauti menjawab Allah menyuruh saya mengambil nyawanya anak muda itu di Sanggaleyya, padahal dia masih ada di dekatmu, karena itu akupun pusing karena anak muda itu ada di sisimu. Setelah sampai di Sanggaleyya anak muda tersebut jalan-jalan di kaki gunung sampai ketemu sebuah gua, dan masuklah anak muda ke 
dalam Gua. Sampai ke dalam Gua, di dalamnya ada Malakalmauti lama menunggu, dan berkata kepada anak muda cepat-cepatlah kesini sudah lama aku menunggumu di sini. Di dalam Gua itu, ada seekor ular besar, dan ular itulah yang memakan anak muda tersebut.

Sebuah hadis menceritakan bahwa sesungguhnya ajal semua hewan itu adalah zikirnya kepada Allah, jadi kalau hewan atau binatang itu terputus berzikir kepada Allah, maka matilah hewan atau binatang tersebut, bukanlah malaikatmaut yang mematikan segala sesuatu. Menurut pendapat ulama hanya Allah Ta'ala sendiri yang mematikan semua makhluk. Mati itu hanya disandarkan kepada Malakal maut, sebagaimana disandarkan mati kepada penyakit, orang terbunuh disandarkan kepada orang yang membunuh. Sejalan dengan firman Allah Ta'ala "Sesungguhnya Allah lah yang memegang nyawa (seseorang) pada saat kematiannya..." (QS. Al-Zumar: 42).

Bahwa jawaban roh ketika diambil oleh Malaikat maut, berkatalah roh kepada Malaikat maut, wahai Malaikat maut aku tidak mau diambil tanpa perintah dari Allah Ta'ala untuk mengambil aku. Malaikat maut menjawab aku telah diperintahkan oleh Allah Ta'ala untuk mengambil kamu. Roh itu menjawab, apa tandanya bahwa kamu telah diperintahkan oleh Allah Ta'ala, padahal ketika aku diciptakan dan dimasukkan ke dalam tubuhku kamu tidak ada (tidak hadir). Karena itu, kembalilah Malakul maut kepada Allah Ta'ala, dan menyampaikan alasan roh, Allah pun membenarkan perkataan roh. Karena itu Allah Ta'ala menyuru Malaikat maut, pergilah kamu ke surga mengambil sebuah delima (taffahu) dan tulislah nama-Ku (Bis-millahir-rahmanirrahim) pada buah tersebut, kemudian perlihatkanlah. Maka pergilah Malaikat maut ke surga dan mengambil sebuah delima kemudian menulis nama Allah yaitu "Bismillahirrahmanirrahim" kemudian dia perlihatkan ke roh tersebut di saat itu keluarlah roh dari jasadnya dengan senang hati.

Dalam sebuah riwayat dikatakan; Apabila Allah menghendaki mati seseorang dari hambaNya, datanglah Malaikat maut mendekati orang yang akan meninggal ingin mengambil nyawanya, tapi mengalirlah zikir keluar dari mulutnya, dan mengucapkan tidak bisa kamu mengambil nyawaku dari mulutku karena selalu bezikir dan mengaji serta membaca hadis karena Allah. Maka kembalilah Malaikat maut kepada Allah Ta'ala minta ampun, dan menyampaikan perkataan mulut orang yang akan mati, Allah pun menyuruh Malaikat maut mengeluarkan dari anggota tubuhnya yang lain, maka pergilah ke tangannya, tangannya pun berkata kepada Malaikat maut tidak bisa kamu ambil nyawaku dari saya, karena selalu memberikan sedekah, banyak kitab ditulis, banyak kepala anak yatim yang di usap-usap dan dibelai-belai kasih sayang, pergi lagi ke kakinya, kakinya pun berkata tidak bisa kamu mengambil nyawaku dari kakiku, karena selalu pergi salat berjama'ah di Masjidmasjid, salat jum'at, salat id, dan biasa juga pergi mengunjungi para ulama untuk mendapatkan ilmu pengetahuan, mengaji Alquran.

Setelah itu, pergi lagi Malaikat maut ke telinganya, berkatalah telingannya, tidak bisa kamu mengambil rohku dari telingaku, karena sering mendengarkan bacaan Alquran, ceramah-ceramah agama dan sebagainya. Pergi lagi Malaikat maut ke matanya, dan berkatalah matanya, tidak bisa kamu mengambil roh ku dari mataku, karena sering melihat Alquran, sering memandang wajah para ulama. Kembalilah Malaikat maut menyembah kepada Allah dan minta ampun, seraya berkata Wahai Tuhan Engkau telah perintahkan aku mengambil roh salah seorang hamba-Mu, tapi mengapa dia berkata demikian kepadaku? Berkatalah Allah Ta'ala kepada Malaikat maut, tulislah nama-Ku di atas telapak tanganmu, kemudian perlihatkan kepada hamba-Ku yang beriman. Segeralah Malaikat maut menulis nama Allah di atas telapak tangannya, kemudian dia memperlihatkan hamba Allah Ta'ala yang beriman, barulah keluar Roh orang yang beriman dari jasadnya dengan suka ria, senang hati penuh dengan kebahagiaan.

Di tempat lain dalam kittak badul akhirat juga menceritakan bila seseorang hamba Allah telah meninggal dunia terbagilah atas lima bagian, pertama; harta bendanya baginya ahli warisnya, kedua, Nyawa/rohnya bagiannya Malaikat maut; ketiga, dagingnya bagi cacing-cacing dan ulat; keempat, tulang-tulangnya bagi tanah; dan yang kelima amal baiknya adalah baginya orang yang telah dikhianati, disakiti, dizhalimi. Wahai sekalian anak cucu Adam, renungkanlah baik-baik dan pikirkanlah dalam-dalam bagaimana latar belakang keberadaanmu, kalau semua hartamu sudah diambil oleh ahli warismu, nyawamu sudah diambil oleh Malaikat maut, dagingmu yang gemuk sudah dimakan oleh si cacing dan sudah menjadi santapan sinta, tulang-belulangmu sudah hancur termakan tanah, dan semua amal baikmu sudah diambil oleh orang yang sudah dikhianati, ditipu dan dizalimi? 
Telah sirna iman dari dada, meninggalkan dunia tanpa agama, itulah kerugian yang paling besar, penyesalan yang tiada putus tak berguna lagi, mengadu kepada siapa kalau mati tidak bertaubat?

Selain dalam Kittak Badul Akhirat diceritakan tentang kematian, juga diceritakan tentang keniscayaan hari kiamat dan segala hal ihwalnya, neraka dan segala azabnya serta surga dan segala nikmatnya.

\section{Aqiqah}

Hari puncak tradisi angngalle alio, keluarga si mayit melakukan penyembelihan hewan yang diperuntukkan bagi si mayit. Masyarakat Turatea meyakini bahwa hewan yang disembelih itu dapat menjadi kendaraan mereka nantinya di hari akhirat kelak. Penyembelihan binatang dikenal dengan istilah "samballe aqiqah" yaitu seekor atau dua ekor kambing yang disembelih sebagai aqiqah bagi keluarga atau orang yang baru meninggal. Sejalan dengan kepercayaan masyakat Turatea ini dapat dilihat dari isi Kittak Badul Akhirat dikatakan:

Ketika mereka dibangkitkan dari kubur pada hari kiamat berfirmanlah Allah kepada malaikat wahai malaikat janganlah biarkan hamba-Ku berjalan kaki, karena mereka sering mengendarai, berikanlah kurbannya dan 'aqiqahnya agar mereka mengendarai menuju kepada-Ku.

Bahkan ada juga dari masyarakat yang berkeyakinan bahwa pada hari puncak acara angngalle alio ini, roh orang yang baru saja meninggal turut juga menikmati suguhan daging sembelihan tersebut. Terkadang juga, disaksikan bagaimana tindakan masyarakat Turatea dalam mendandani hewan yang akan disembelih dengan cara menyisir, dipakaikan dengan kain putih/kaci, dan sekaligus juga disiapkan beras, kelapa dan gula merah. Masyarakat Turatea menyebutnya dengan nama "jakjakkan", setelah hewan disembelih, jakjakkan ini pun diberikan kepada imam yang menyembelihnya.

Pada penutupan acara puncak angngalle alio ini, diadakanlah akpatamma artinya menamatkan pengajian Alquran dengan berzikir bersama dipimpin oleh Imam kampung, peserta zikir adalah orang-orang yang ikut mengaji pada setiap malam sebelum acara puncak. Setelah akpatamma selesai dilaksanakan, diadakanlah jabat tangan oleh salah seorang anggota keluarga yang diberikan amanah dengan para peserta zikir atau peserta akpatamma', dan khusus kepada Imam yang memimpin pengajian setiap malam diberikan passidakkah berupa seperangkat alat tidur seperti ranjang, dipan lengkap dengan lemari. Ini juga merupakan budaya khas bagi masyarakat turatea.

\section{Ta'ziyah}

Seiring dengan kemajuan zaman dan peningkatan ilmu pengetahuan masyarakat akan selalu berproses. Masyarakat akan senantiasa berubah di semua tingkat kompleksitas internalnya. Di tingkat makro terjadi perubahan ekonomi, politik, dan kultur. Di tingkat mezo terjadi perubahan kelompok, komunitas, dan organisasi. Di tingkat mikro terjadi perubahan interaksi dan perilaku individual (Pior Sztompka, 2004: 65). Masyarakat mengalami perubahan, pertanyaanya apakah perubahan sebuah regress atau progress? (Astrid S. Susanto, 1983: 158).

Dalam masyarakat Islam pada umumnya dikenal tazkirah sebagai acara ta'ziyah agar dijadikan sebagai nasehat atau pelajaran untuk menghadapi kematian, bekal-bekal apa saja yang akan dibawa menuju kampung akhirat (Abdul Wahab Sayidi, tt: 23-27). Tak ketinggalan pula, masyarakat Turatea dari waktu ke waktu mengalami perubahan hingga dewasa ini, maka angngalle alio bagi masyarakat Turatea mengalami juga perkembangan dan kemajuan ditandai dengan tambahan acara pada puncak acara, yakni ta'ziyah/tazkiyah. Dalam acara ini ta'ziyah keluarga si mayit mengundang semua keluarga, sahabat, tetangga, teman-sejawat dan sebagainya, untuk hadir pada malam yang telah ditetapkan sebagai malam puncak acara, kemudian juga mengundang seorang ahli agama/ustaz/ muballigh untuk memberikan taushiyah/ceramah agama kepada para undangan yang hadir di tempat yang telah disiapkan. Hal ini dijelaskan dalam hadis riwayat Tirmizi dari Nabi saw, beliau bersabda:

\section{$"$ Akii $\wedge$ liji $\quad j \& \wedge$}

Artinya: Barang siapa menta'ziyai saudaranya yang kena musibah niscaya Allah memberikan pakaian yang sangat halus pada hari kiamat (Imam Nawawi, 2009: 23).

Sementara Ibnu Majah meriwayatkan dari Umar bin Hazmin dari Nabi saw beliau bersabda: 
Artinya: Tiadalah orang yang datang melayak kepada saudaranya yang mendapat musibah, melainkan Allah memberikan pakaian kehormatan (dalam surga) pada hari kiamat (Imam Nawawi, 2009: 24).

\section{PENUTUP}

Angngalle alio merupakan kepercayaan masyarakat Turatea dalam memperingati hari kematian. Tradisi ini dapat dikatakan sebagai penawar duka dan pelipur lara bagi keluarga yang ditinggalkannya di alam fana ini. Aktivitas dan perilaku sosial budaya, adat istiadat dipengaruhi oleh sistem kepercayaan masyarakat Turatea. Wujud aktivitas dan perilaku sosial budaya yang mereka lakukan merupakan hasil refleksi penghayatan, pemahaman dan pengetahuan mereka terhadap sistem kepercayaan yang tumbuh dan berkembang dalam kehidupan masyarakat Turatea.

Dalam tradisi angngalle alio terdapat pembacaan Alqur'an dan pembacaan Kittak Badul Akhirat yang berisi pesan-pesan religius yang sangat berguna untuk keluarga yang ditinggalkan untuk meniti kehidupan masa mendatang.

\section{Ucapan Terima Kasih}

Kepada redaksi jurnal Al-Qalam, kami mengucapkan terima kasih telah memuat tulisan ini. Terkhusus kepada informan kunci kami di lapangan yang telah memberikan informasi yang berharga dalam penelitian ini, kami ucapkan terima kasih, serta kepada semua pihak yang tidak bisa kami sebutkan satu-persatu.

\section{DAFTAR PUSTAKA}

Alquran dan Al-Hadis.

Agus. Bustanuddin. 2007. Agama Dalam Kehidupan Manusia: Pengantar Antropologi Agama. Jakarta: Rajawali Press.

Departemen Pendidikan dan Kebudayaan. 2000. Kamus Bahasa Indonesia. Jakarta: Departemen Pendidikan dan Kebudayaan.

Endraswara, Suwardi. 2006. Metode, Teori, Teknik Penelitian Kebudayaan- Ideologi, Epistemologi, dan Aplikasi . Yogyakarta: Pustaka Widyatama.

Gunawan, Ary H. t.t. Sosiologi Pendidikan Suatu
Analisis Sosial tentang Pelbagai Problem Pendidikan. Jakarta: Rineka Cipta.

Haq, Hamka. 2009. Islam Rahmah Untuk Bangsa. Jakarta: RMBooks

Hartomo dkk. 1999. Ilmu Sosial Dasar. Jakarta: Bumi Aksara.

Laksono. 1999. Teori Budaya. Yogyakarta: Pustaka Pelajar.

Liliweri, Alo. 2005. Prasangka dan Konflik: Komunikasi Lintas Budaya Masyarakat Multikultur. Yogyakarta: LKiS.

Miles dan Huberman. 1984. Qualitatif Data Analisis. Beverly Hill: Sage Publication.

Munawwir, Ahmad Warson. 1984. Kamus AlMunawwir Arab-Indonesia Terlengkap.

Yogyakarta: Pesantren Krapyak.

Nawawi, Imam. 2009. Adah Menjenguk dan Melawat. Jakarta: Gramedia.

Puslitbang Kehidupan Keagamaan Badan Litbang dan diklat Kementerian Agama. 2013. Keluarga dan Toleransi Beragama Di Era Reformasi. Jurnal Jurnal Harmoni, Nomor 2, Volume 12. Jakarta: Puslitbang Kehidupan Keagamaan Kementerian Agama.

Puslitbang Kehidupan Keagamaan Badan Litbang dan diklat Kementerian Agama, 2014. Dinamika Integrasi dan Komunikasi Kehidupan Keagamaan, Jurnal Harmoni, Nomor 1, Volume 13. Jakarta: Puslitbang Kehidupan Keagamaan Kementerian Agama.

Qadir, Ahmad Abdul. 2009.Akhbaral-Akhirah (Kitab Kana-kananna alio ribokowwa). Makassar: Balai Penelitian dan Pengembangan Agama.

Said, Nurman. 2009. Masyarakat Muslim Makassar:

Studi Pola-pola Integrasi Sosial antara Muslim Pagama dengan Muslim Sossorang. Yogyakarta: Disertasi UIN Sunan Kali Jaga.

Sayidi, Abdul Wahab. tt. Mukhtasar Tazkirah alQurtubi HI Qutub al-Rabbani wa al-'Ilm alSamad. tp.

Soehadha, Moh. 2008. Metodologi Penelitian Agama. Yogyakarta: UIN Sunan Kalijaga.

Susanto, Astrid S. 1983. Pengantar Sosiologi dan Perubahan Sosial. Jakarta: Bina Cipta.

Sztompka, Piotr. 1993. Sosiologi Perubahan Sosial. Jakarta: Prenada.

Upe, Ambo. 2010. Tradisi Aliran dalam Sosiologi. Jakarta: Rajawali Press. 
Artinya: Tiadalah orang yang datang melayak kepada saudaranya yang mendapat musibah, melainkan Allah memberikan pakaian kehormatan (dalam surga) pada hari kiamat (Imam Nawawi, 2009: 24).

\section{PENUTUP}

Angngalle alio merupakan kepercayaan masyarakat Turatea dalam memperingati hari kematian. Tradisi ini dapat dikatakan sebagai penawar duka dan pelipur lara bagi keluarga yang ditinggalkannya di alam fana ini. Aktivitas dan perilaku sosial budaya, adat istiadat dipengaruhi oleh sistem kepercayaan masyarakat Turatea. Wujud aktivitas dan perilaku sosial budaya yang mereka lakukan merupakan hasil refleksi penghayatan, pemahaman dan pengetahuan mereka terhadap sistem kepercayaan yang tumbuh dan berkembang dalam kehidupan masyarakat Turatea.

Dalam tradisi angngalle alio terdapat pembacaan Alquran dan pembacaan Kittak Badul Akhirat yang berisi pesan-pesan religius yang sangat berguna untuk keluarga yang ditinggalkan untuk meniti kehidupan masa mendatang.

\section{Ucapan Terima Kasih}

Kepada redaksi jurnal Al-Qalam, kami mengucapkan terima kasih telah memuat tulisan ini. Terkhusus kepada informan kunci kami di lapangan yang telah memberikan informasi yang berharga dalam penelitian ini, kami ucapkan terima kasih, serta kepada semua pihak yang tidak bisa kami sebutkan satu-persatu.

\section{DAFTAR PUSTAKA}

Alquran dan Al-Hadis.

Agus. Bustanuddin. 2007. Agama Dalam Kehidupan Manusia: Pengantar Antropologi Agama. Jakarta: Rajawali Press.

Departemen Pendidikan dan Kebudayaan. 2000. Kamus Bahasa Indonesia. Jakarta: Departemen Pendidikan dan Kebudayaan.

Endraswara, Suwardi. 2006. Metode, Teori, Teknik Penelitian Kebudayaan- Ideologi, Epistemologi, dan Aplikasi . Yogyakarta: Pustaka Widyatama.

Gunawan, Ary H. t.t. Sosiologi Pendidikan Suatu
Analisis Sosial tentang Pelbagai Problem Pendidikan. Jakarta: Rineka Cipta.

Haq, Hamka. 2009. Islam Rahmah Untuk Bangsa. Jakarta: RMBooks

Hartomo dkk. 1999. Ilmu Sosial Dasar. Jakarta: Bumi Aksara.

Laksono. 1999. Teori Budaya. Yogyakarta: Pustaka Pelajar.

Liliweri, Alo. 2005. Prasangka dan Konflik: Komunikasi Lintas Budaya Masyarakat Multikultur. Yogyakarta: LKiS.

Miles dan Huberman. 1984. Qualitatif Data Analisis. Beverly Hill: Sage Publication.

Munawwir, Ahmad Warson. 1984. Kamus AlMunawwir Arab-Indonesia Terlengkap. Yogyakarta: Pesantren Krapyak.

Nawawi, Imam. 2009. Adah Menjenguk dan Melawat. Jakarta: Gramedia.

Puslitbang Kehidupan Keagamaan Badan Litbang dan diklat Kementerian Agama. 2013. Keluarga dan Toleransi Beragama Di Era Reformasi. Jurnal Jurnal Harmoni, Nomor 2, Volume 12. Jakarta: Puslitbang Kehidupan Keagamaan Kementerian Agama.

Puslitbang Kehidupan Keagamaan Badan Litbang dan diklat Kementerian Agama, 2014. Dinamika Integrasi dan Komunikasi Kehidupan Keagamaan, Jurnal Harmoni, Nomor 1, Volume 13. Jakarta: Puslitbang Kehidupan Keagamaan Kementerian Agama. Qadir, Ahmad Abdul. 2009. Akhbaral-Akhirah (Kitab Kana-kananna alio ribokowwa). Makassar: Balai Penelitian dan Pengembangan Agama.

Said, Nurman. 2009. Masyarakat Muslim Makassar: Studi Pola-pola Integrasi Sosial antara Muslim Pagama dengan Muslim Sossorang. Yogyakarta: Disertasi UIN Sunan Kali Jaga.

Sayidi, Abdul Wahab. tt. Mukhtasar Tazkirah alQurtubi HI Qutub al-Rabbani wa al-'Ilm alSamad. tp.

Soehadha, Moh. 2008. Metodologi Penelitian Agama. Yogyakarta: UIN Sunan Kalijaga.

Susanto, Astrid S. 1983. Pengantar Sosiologi dan Perubahan Sosial. Jakarta: Bina Cipta.

Sztompka, Piotr. 1993. Sosiologi Perubahan Sosial. Jakarta: Prenada.

Upe, Ambo. 2010. Tradisi Aliran dalam Sosiologi. Jakarta: Rajawali Press. 